or indirectly the rate of growth of a plasmagene identical with, or precursor of, an enzyme (see Spiegelman ${ }^{5}$ ).

By comparing in vitro suitable enzyme systems of the parent strain with those of 'adaptable' mutants it may be possible to investigate the first and second alternatives. On the other hand, the third alternative can be verified by investigating whether continued sub-culture of an 'adaptable' mutant on a medium supplying the growth factor ultimately leads to irretrievable loss of the adaptability; that is, ex hypothesi to the loss of every particle of plasmagene ${ }^{6}$.

It seems that investigation of these 'adaptable' mutants might show whether 'adaptability' is a property of the enzyme-certain enzymes being adaptive and others not-or of the cell which produces the enzyme. The relevance for the understanding of the relationships between genes, other self-duplicating cell structures and enzymes is clear ${ }^{4,5}$.

P. Devi

G. Ponteconvo

Department of Genetics,

University of Glasgow, and

Hannah Dairy Research Institute, Kirkhill, Ayr. July 3.

${ }^{1}$ Luria, S. E., Bact. Rev., 11, 1, 40 (1947).

'Stone, S. W., Wyss, O., and Haas, F., Proc. Nat. Acad. Sci., 33, 59, 66 (19347).

${ }^{\circledR}$ Lederberg, J., and Tatum, E. L., J. Biol. Chem., 165, 381, 82 (1946).

- Beadle, G. W., Chem. Rev., 37, 15, 96 (1945).

s Muller, H. J., Proc. Roy. Soc., B, 134, 1, 37 (1947). Spiegelman, S., Cold Spring Harbor Symp., 11, 256, 77 (1947). Mcllwain, H., Nature, 158, 898, 902 (1946). Hinshelwood, O. H., "The Chemical Kinetics of the Bacterial Cell" (Oxford, 1946).

sf. the situation in Paramecium: Sonneborn, 'T. M., "Advances in Genetics", 1, 263, 358 (1947).

\section{Anode Phenomena in Molten Electrolytes}

Fredenhagen and Krefft ${ }^{2}$ have shown that, when molten KF.HF is electrolysed using a graphite anode, the anode is not 'wetted' by the electrolyte. The same effect has been noted by other investigators as, for example, $\mathrm{Cady}^{2}$.

In the course of experiments carried out in this Laboratory we have confirmed the observations of Fredenhagen and Cady, and have further shown that a similar apparent absence of 'wetting' of the anode by the electrolyte takes place with amorphous carbon anodes in molten KF.2HF at temperatures between $80^{\circ}$ and $110^{\circ} \mathrm{C}$. We have also observed that all the fluorine formed at the anode leaves at the solidliquid interface, and that, at least up to a current density of the order of 0.5 amp. per sq. in., no gas is evolved as bubbles which rise through the electrolyte in the usual way. Under certain conditions similar effects have been observed at carbon cathodes during the electrolysis of KF.2HF. This observation has not been previously reported.

It is suggested that the observed effects are a consequence of a wetting angle at the electrode electrolyte interface greater than $90^{\circ}$. It is possible that a relation exists between the actual value of the wetting angle and the maximum current density at which the effect can be observed. Liberation of gas at such an interface must result in the formation of flattened or lenticular bubbles. Möller ${ }^{3}$ and Frumkin and Kabanov ${ }^{4}$ have reported such bubbles on horizontal surfaces. When, however, lenticular bubbles are formed at vertical solid surfaces, the mechanism of gas escape may become quite different from that observed when the liquid makes with the solid a contact angle of less than $90^{\circ}$. In such circumstances, any tendency for bubbles to break away from the solid (electrode) surface is reduced and transfer of gas to the surface takes place by a process of coalescence and passing on of gas from bubble to bubble, or by slipping of bubbles up the electrode surface. Microscopic examination of the discharge of fluorine at a carbon surface, when KF.2HF is electrolysed in a 'Perspex' or polystyrene container, has confirmed the correctness of this explanation.

Many attempts have been made to provide an adequate explanation of the so-called 'anode effect' which commonly occurs in fused salt electrolysis". So recently as 1944, Koehler ${ }^{6}$ attributes to v. Wartenberg ${ }^{7}$ the credit for having established the true nature of the phenomenon; but the literature of the subject shows many inconsistencies and no really satisfactory theory has so far been suggested.

We suggest that the anode effect may well represent a special and extreme case of the conditions to which reference is made above, in which event it should be possible to study the anode effect from a new point of view.

\section{A. J. RUDGE \\ W. N. HowelL H. HILL}

Imperial Chemical Industries, Ltd.,

Runcorn Laboratory, Cheshire. July 1 .

1 Fredenhagen and Krefft, $Z$. Electrochem., 35, 670 (1929).

- Cady, Rogers and Carlson, J. Ind. Eng. Chem., 34, 443 (1942).

3 Möller, Z. phys. Chem., 65, 226 (1908).

- Frumkin and Kabanov, Z. phys. Chem., 165, 433 (1933).

- Taylor, Trans. Electrochem. Soc., 67, 301 (1925).

"Koehler, "Principles and Applications of Electrochemistry" (J Wiley and Sons, 1944).

${ }^{7}$ v. Wartenberg, $Z$. Electrochem., 32, 330 (1926).

\section{A New Human Iso-Agglutinin Subdividing the MN Blood Groups}

THE serum of a puerperal patient, whose fifth pregnancy resulted in the birth of a macerated œdematous fœtus, has been found to contain a previously unidentified agglutinin for human red cells. The patient's blood was group $A M N R h$ negative (cde/cde), and her husband's blood group $A M R h_{1}(C D e / C D e)$. In addition to the new agglutinin the serum contained an incomplete anti- $D$ antibody.

Positive agglutination reactions were obtained with the bloods of 123 (48.6 per cent) in a total of 253 individuals selected at random from a sample of the Australian population. There was no relationship to the $A B O$ or $R h$ groups, and the percentage of positive reactions obtained made an association with the $P$, Lutheran, Kell and Lewis groups unlikely. An association with these groups was excluded when direct comparisons were made at the Medical Research Council Blood Group Research Unit, London, where a relationship to the $M N$ groups was discovered.

Tests on a further 140 subjects confirmed this relationship, as is shown by the following results:

$\begin{array}{lrcrr}\text { Results } & M & M N & N & \text { Total } \\ \text { Positive } & 30 & 40 & 13 & 83 \\ \text { Negative } & 9 & 27 & 21 & 57 \\ \text { Total } & 39 & 67 & 34 & 140\end{array}$

Of the $M$ bloods tested 77 per cent gave positive reactions, whereas only 38 per cent of the $N$ bloods were agglutinated. This finding is significant, $\chi^{2}$ equalling $11 \cdot 2$ for one degree of freedom.

The agglutinin acted most strongly at $37^{\circ} \mathrm{C}$., but was also active at lower temperatures. No dosage 